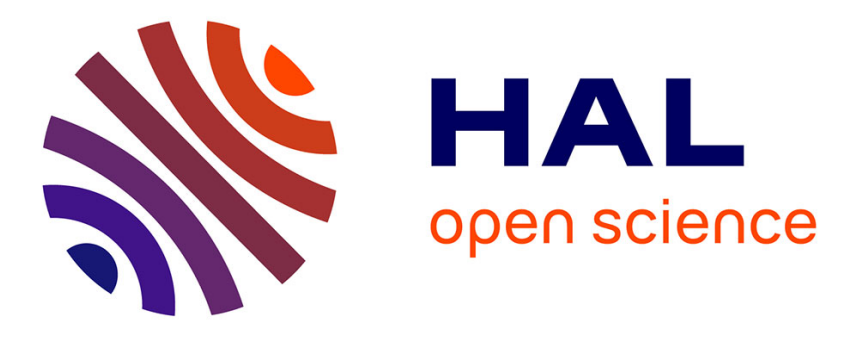

\title{
Low-noise mid-infrared supercontinuum generation in a silicon-based chip
}

Milan Sinobad, Alberto Della Torre, Remi Armand, Barry Luther-Davies, Pan Ma, Stephen Madden, Arnan Mitchell, David Moss, Jean-Michel Hartmann, Jean-Marc Fedeli, et al.

\section{To cite this version:}

Milan Sinobad, Alberto Della Torre, Remi Armand, Barry Luther-Davies, Pan Ma, et al.. Low-noise mid-infrared supercontinuum generation in a silicon-based chip. Advanced Solid State Lasers OSA laser congress 2020, Oct 2020, Washington, United States. pp.AW5A.3, 10.1364/ASSL.2020.AW5A.3 . hal-03298891v2

\section{HAL Id: hal-03298891 \\ https://hal.science/hal-03298891v2}

Submitted on 12 Sep 2021

HAL is a multi-disciplinary open access archive for the deposit and dissemination of scientific research documents, whether they are published or not. The documents may come from teaching and research institutions in France or abroad, or from public or private research centers.
L'archive ouverte pluridisciplinaire HAL, est destinée au dépôt et à la diffusion de documents scientifiques de niveau recherche, publiés ou non, émanant des établissements d'enseignement et de recherche français ou étrangers, des laboratoires publics ou privés. 


\title{
Low-noise mid-infrared supercontinuum generation in a silicon-based chip
}

\author{
Milan Sinobad, ${ }^{1}$ Alberto Della Torre, ${ }^{1}$ Remi Armand, ${ }^{1}$ Barry Luther-Davies, ${ }^{2}$ Pan Ma, ${ }^{2}$ Stephen \\ Madden,르 Arnan Mitchell, ${ }^{3}$ David J. Moss, ${ }^{4}$ Jean-Michel Hartmann, ${ }^{5}$ Jean-Marc Fedeli, ${ }^{5}$ Christelle \\ Monat, ${ }^{1}$ and Christian Grillet ${ }^{1}$ \\ 1 Université de Lyon, Ecole Centrale de Lyon, Institut des Nanotechnologies de Lyon (INL), 69131 Ecully, France \\ 2 Laser Physics Centre, Australian National University, Canberra, ACT 0100, Australia \\ 3 School of Engineering, RMIT University, Melbourne, VIC 3001, Australia \\ 4 Optical Sciences Centre, Swinburne University of Technology, Hawthorn, VIC 3122, Australia \\ 5 Université Grenoble Alpes and CEA, LETI, 17 Avenue des Martyrs 38054 Grenoble, France
}

\begin{abstract}
We report the first mid-infrared octave-spanning supercontinuum in an all-normal dispersion silicon-based chip. We generated coherent supercontinuum from 2.8 to $5.7 \mu \mathrm{m}$ in a silicon-germanium waveguide pumped at $4 \mu \mathrm{m}$ with 200 fs pulses. (C) 2020 The Author(s)
\end{abstract}

Many important molecules, in particular organic species, have sharp absorption lines in the midinfrared (mid-IR, 3 - $15 \mu \mathrm{m}$ ), allowing for sensing applications in air quality and environmental monitoring [1]. Despite recent progess, mid-IR technologies are still limited in their range of applications, largely due to the size of the devices and the prohibitive costs of the instruments. Achieving a small footprint low-cost sensing platform, with an integrated supercontinuum (SC) source, is a long desired objective in the mid-IR silicon photonics community [2,3]. Silicon germanium-on-silicon (SiGe-on-Si) is a particularly appealing Si-based platform as SiGe with reasonably strong nonlinear, and low-loss waveguides in the mid-IR [4]. In this platform, we managed to demonstrate SC from 3 to $8.5 \mu \mathrm{m}$ experimentally [5]. More recently, we reported high coherence of an SC spanning from 2.6 to $6.2 \mu \mathrm{m}$ at frequencies separated by an octave, as required for $f$ to $2 f$ selfreferencing schemes used to stabilize pulse [6].

SC generation in all-normal dispersion (ANDi) regime is a low-noise process that maintains a single pulse, allowing for high-precision spectroscopy [7]. So far, SC generation in the ANDi regime was reported in various fiber platforms [8-11] and in a chalcogenide waveguide [12], without any discussion about the phase spectral coherence properties. Recently, we demonstrated a post-fabrication technique used for trimming dispersion from anomalous to all-normal [13]. In this work, we report what we believe to be the first octave-spanning fully coherent supercontinuum in an ANDi waveguide on a silicon-based chip in the mid-infrared.

Our SiGe ( $40 \%$ Ge in alloy) waveguides, with $5.0 \mu \mathrm{m} \times 2.7 \mu \mathrm{m}$ cross-section were fabricated at CEA Leti. A SiGe layer was epitaxially grown on the Si substrate. The waveguides were patterned using deep-UV lithography, and finally formed by deep reactive-ion etching. Fig. 1a shows an SEM image of the fabricated waveguide. We designed the waveguides to operate in the ANDi regime with low group-velocity dispersion (GVD $<100$ ps $/ \mathrm{nm} / \mathrm{km}$ ) across an octave bandwidth between 3 and $6 \mu \mathrm{m}$ in TM polarization (see Fig. 1a, bottom).

We characterized our waveguides using a standard butt-coupling setup. We measured losses as low as 0.3 $\mathrm{dB} / \mathrm{cm}$ between 4 and $5 \mu \mathrm{m}$ in TM polarization. We then performed SC spectrum measurements by pumping a $2 \mathrm{~cm}$ long waveguide with 200 femtoseconds, $63 \mathrm{MHz}$ repetition rate pulses delivered by a Miropa-fs OPA operating at $4 \mu \mathrm{m}$. Fig. $1 \mathrm{~b}$ shows the measured output spectra obtained by pumping the waveguide with low (blue solid curve) and high (black solid curve) input power. In the latter case, a SC spanning over an octave from 2.8 to $5.7 \mu \mathrm{m}$ was obtained with $40 \mathrm{~mW}(5.7 \mathrm{~kW}$ ) coupled average (peak) power. Our simulations (dashdotted curves in Fig. 1b) are in good agreement with the experimentally generated spectra. We calculated the degree of first-order coherence $\mathrm{g}_{12}$ of the high power spectrum from 50 independent simulations. The calculated coherence is high, with $g_{12}$ equal to unity over the entire bandwidth (red curve in Fig. 1b). 

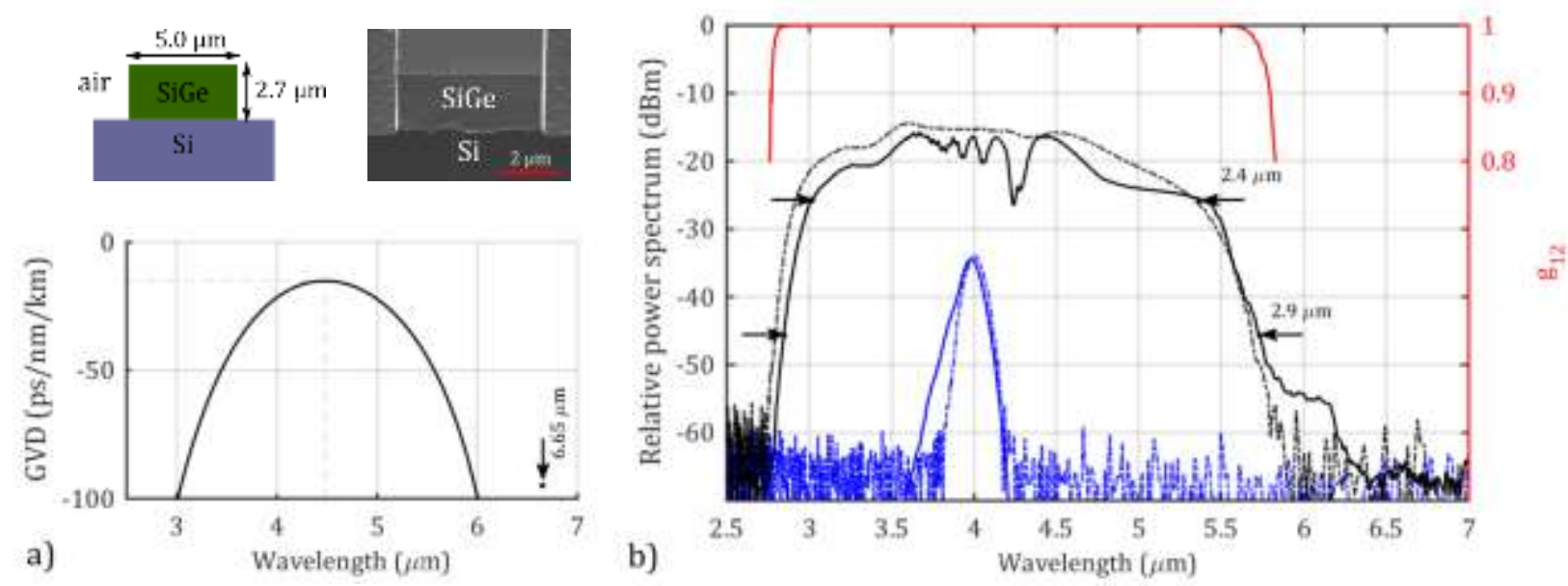

Fig. 1 a) Calculated group velocity dispersion GVD for $5.0 \mu \mathrm{m} \times 2.7 \mu \mathrm{m}$ cross-section air-clad $\mathrm{Si}_{0.6} \mathrm{Ge}_{0.4} / \mathrm{Si}$ waveguide. The SEM image of the waveguide is provided on top, b) Measured (solid) and simulated (dash-dotted) low-power (blue) and SC (black) spectra in the TM polarization. The top red curve shows the calculated coherence of the SC spectrum.

SC in all-normal dispersion waveguides does not suffer from polarization noise as in optical fibers [14]. Moreover, when compared to SC in anomalous dispersion waveguides, the noise due to the modulation instability is inhibited. Thus, the SC in ANDi waveguides can enable an ultra-low noise source.

In conclusion, we have demonstrated a fully coherent octave-spanning supercontinuum in an all-normal dispersion SiGe-on-Si waveguide. We found good agreement between measurements and simulations, allowing us to numerically confirm the full coherence of the generated SC across its entire bandwidth. The SC covers the critical 3 to $5 \mu \mathrm{m}$ molecule vibration absorptions region, and thanks to its flat spectrum with low noise can enable high-precision on-chip spectroscopy.

Funding: Agence Nationale de la Recherche (ANR) MIRSiCOMB (ANR-17-CE24-0028), European ERC grant GRAPHICS (648546); We acknowledge the support of the LIA ALPhFA

\section{References}

[1] G. Z. Mashanovich, C. J. Mitchell, J. S. Penades, A. Z. Khokhar, C. G. Littlejohns, W. Cao, et al., "Germanium mid-infrared photonic devices," J. Lightw. Technol., vol. 35, 2017.

[2] R. Soref, "Mid-infrared photonics in silicon and germanium," Nat. Photonics, vol. 4, pp. 495-497, 2010.

[3] D. Marris-Morini, V. Vakarin, J. M. Ramirez, Q. Liu, A. Ballabio, J. Frigerio, et al., "Germanium-based integrated photonics from nearto mid-infrared applications," Nanophotonics, vol. 0, 2018.

[4] N. K. Hon, R. Soref, and B. Jalali, "The third-order nonlinear optical coefficients of Si, Ge, and Si1- xGex in the midwave and longwave infrared," J. Appl. Phys., vol. 110, pp. 11301-11301, 2011.

[5] M. Sinobad, C. Monat, B. Luther-Davies, P. Ma, S. Madden, D. J. Moss, et al., "Mid-infrared octave spanning supercontinuum generation to 8.5um in silicon-germanium waveguides," Optica, vol. 5, pp. 360-366, 2018/04/20 2018.

[6] M. Sinobad, A. Della Torre, R. Armand, B. Luther-Davies, P. Ma, S. Madden, et al., "High coherence at f and 2f of mid-infrared supercontinuum generation in silicon germanium waveguides," IEEE J. Sel. Top. Quantum Electron., vol. 26, 2020.

[7] A. M. Heidt, J. S. Feehan, J. H. V. Price, and T. Feurer, "Limits of coherent supercontinuum generation in normal dispersion fibers," J. Opt. Soc. Am. B, vol. 34, pp. 764-775, 2017.

[8] N. Nishizawa and J. Takayanagi, "Octave spanning high-quality supercontinuum generation in all-fiber system," Journal of the Optical Society of America B, vol. 24, pp. 1786-1792, 2007/08/01 2007.

[9] A. M. Heidt, "Pulse preserving flat-top supercontinuum generation in all-normal dispersion photonic crystal fiber," J. Opt. Soc. Am. B, December 26, 20092010.

[10] A. Al-Kadry, L. Li, M. El Amraoui, T. North, Y. Messaddeq, and M. Rochette, "Broadband supercontinuum generation in all-normal dispersion chalcogenide microwires," Opt. Lett., vol. 40, pp. 4687-90, Oct 152015.

[11] K. Jiao, J. Yao, Z. Zhao, X. Wang, N. Si, X. Wang, et al., "Mid-infrared flattened supercontinuum generation in all-normal dispersion tellurium chalcogenide fiber," Optics Express, vol. 27, pp. 2036-2043, 2019/02/04 2019.

[12] Y. Yu, X. Gai, P. Ma, K. Vu, Z. Yang, R. Wang, et al., "Experimental demonstration of linearly polarized 2-10 mum supercontinuum generation in a chalcogenide rib waveguide," Opt. Lett., vol. 41, pp. 958-61, Mar 012016.

[13] M. Sinobad, A. Della Torre, B. Luther-Davis, P. Ma, S. Madden, S. Debbarma, et al., "Dispersion trimming for mid-infrared supercontinuum generation in a hybrid chalcogenide/silicon-germanium waveguide," J. Opt. Soc. Am. B, vol. 36, pp. A98-A104, 2019.

[14] I. Bravo Gonzalo, R. D. Engelsholm, M. P. Sorensen, and O. Bang, "Polarization noise places severe constraints on coherence of allnormal dispersion femtosecond supercontinuum generation," Sci. Rep., vol. 8, p. 6579, Apr 262018. 